\title{
Layanan Konseling Bagi Atlet Persatuan Tenis Meja Pade Angen Mataram 2020
}

\author{
Aminullah $^{1}$ Nurdin $^{2}$ Ismail Marzuki $^{3}$ \\ ${ }^{1}$ Fakultas Ilmu Keolahragaan Dan Kesehatan Masyarakat, UNDIKMA Jalan Pemuda No. 59 A \\ Gomong Mataram \\ ${ }^{2}$ Fakultas Ilmu Keolahraga dan Kesehatan Masyarakat, UNDIKMA Jalan Pemuda No. 59 A Gomong \\ Mataram \\ ${ }^{3}$ Fakultas Ilmu Keolahragaan Dan Kesehatan Masyarakat, UNDIKMA Jalan Pemuda No. 59 A \\ Gomong Mataram \\ UNDIKMA Jalan Pemuda No. 59 A Gomong Mataram \\ Email: $\underline{\text { aminsasaki@gmail.com, nurdin@ikipmataram.ac.id, ismailmarzuki@ikipmataram.ac.id }}$
}

\begin{abstract}
The background of the community service activity between the Program and the Tennis Association of the Psychology Study Program of UNDIKMA (Department of Sports and Counseling Guidance). these are as follows. In order to achieve optimal performance, athletes need not only to have excellent physical and technical abilities, but also psychological skills (psychological skills). This happens in badminton, which needs guidance from adolescence. The goal of counseling for athletes is to develop nine mental skills for athletes ranging from attitude to concentration. The method used is action research (action research) which includes focus group discussions, interviews, group counseling, observation of match situations to individual counseling. This activity involved technical trainers, physical trainers, teachers, boarders and male and female athletes aged 12-18 years from the single, men's and women's doubles and PB Pade Angen as well as lecturers and students of Psychology UNDIKMA (Department of Sports and Counseling Guidance). This collaboration is under the auspices of a Memorandum of Understanding between the two institutions under the auspices of PB Pade Angen Table Tennis. This activity during July - October 2020 resulted in a counseling program, 2 articles in the accredited electronic media Mandala Mataram Journal.
\end{abstract}

Keywords: Sport Psychology, Athletes, Tenis Tabel, Mental Skills, Counselling

Abstrak. Latar belakang masalah kegiatan pengabdian masyarakat antara Program dan Persatuan Tenis Program Studi Psikologi UNDIKMA (Jurusan Olahraga dan Bimbingan Konseling). ini adalah sebagai berikut. Agar dapat berprestasi optimal, maka atlet tak hanya perlu memiliki kemampuan fisik dan teknik yang prima, tetapi juga membutuhkan keterampilan psikologis (psychological skills). Hal ini terjadi pada dalam cabang olahraga bulutangkis yang butuh pembinaan sejak remaja. Tujuan konseling untuk atlet adalah mengembangkan sembilan keterampilan mental untuk atlet mulai dari sikap sampai konsentrasi. Metode yang digunakan adalah riset aksi (action research) yang mencakup focus group discussion, wawancara, konseling kelompok, observasi situasi pertandingan sampai konseling individual. Kegiatan ini melibatkan pelatih teknik, pelatih fisik, guru, pengurus asrama dan atlet putra dan putri usia 12-18 tahun dari cabang tunggal, ganda putra dan putri serta PB Pade Angen serta dosen dan mahasiswa Psikologi UNDIKMA (Jurusan Olahraga dan Bimbingan Konseling). Kolaborasi ini dipayungi Memorandum of Understanding antar dua institusi di bawah naungan PB Tenis Meja Pade Angen. Kegiatan sepanjang Juli - Oktober 2020 ini menghasilkan program konseling, 2 artikel di media elektronik Jurnal Mandala Mataram yang berakreditasi.

Kata Kunci: Psikologi Olahraga, Atlet, Tenis Meja, Keterampilan Mental, Konseling

PENDAHULUAN

Abdi Masyarakat
Latar belakang tulisan ini adalah sebagai berikut. Sejak 20 Maret 1996, Persatuan Tenis 
meja Pade anggen mataram menjadi salah satu klub bulutangkis elit di kota mataram. Keberhasilan pade angen tenis meja sangat berkontribusi bagi atlet tenis meja di Kawasan kota mataram khususnya NTB mengharumkan nama bangsa di kancah nasional.

Menurut A.M Bandi Utama (2004: 2) keterampilan permainan tenis meja meliputi: (1) pegangan (grip), (2) sikap atau posisi bermain (stance), (3) jenis-jenis pukulan (stroke), dan (4) gerakan kaki (foot work). Tiap-tiap keterampilan memiliki peran yang sangat penting dalam permainan tenis meja. Pemain yang memiliki kemampuan yang baik, namun tidak didukung oleh gerakan kaki yang baik, maka pemain tersebut masih kurang sempurna. Oleh karena itu, atlet perlu mendapat latihan dalam menguasai teknik-teknik latihan yang ada dari guru atau pelatihnya.

Permasahan yang diangkat dalam tulisan ini adalah sebagai berikut. Tugas utama atlet adalah bertanding dan performa atlet merupakan hasil dari stamina, kekuatan, fleksibilitas, koordinasi, keterampilan dan kemampuan bermain (Gunarsa, 2008). Sementara studi pustaka menunjukkan bahwa atlet tak cuma butuh keterampilan fisik dan teknik tetapi juga keterampilan psikologis. Keterampilan psikologis (psychological skills) merupakan perilaku hasil belajar untuk dimanfaatkan atlet agar berprestasi, antara lain kepercayaan diri dan motivasi (Anderson, Miles, Mahoney \& Robinson, 2002).

Temuan terhadap atlet Pade Angen Mataram menyimpulkan bahwa belum semua atlet memiliki keterampilan psikologis ini, sebagaimana tampak pada masih lemahnya mencapai kematangan emosi yang mereka butuhkan untuk mengatasi stres (Putri, 2016). Keterampilan psikologis terbukti penting melahirkan sang juara (Soerjoatmodjo, Moningka \& Angkawijaya, 2018). Hal ini yang menjadi tujuan pengabdian yaitu menjawab kebutuhan peningkatan keterampilan psikologis atlet Persatuan Tenis meja Pade anggen mataram agar mereka dapat berprestasi optimal.

Segala upaya menghasilkan atlet berprestasi termasuk dalam psikologi olahraga.
Psikologi olahraga bertujuan mengidentifikasi faktor psikologis yang mempengaruhi partisipasi dan performa individu di bidang olahraga serta intervensi peningkatan prestasi dan pengembangan pribadi (Williams \& Straub, 2010).

Salah satu bentuknya adalah penguasaan keterampilan psikologis oleh atlet. Karakteristik atlet yang memiliki keterampilan psikologis antara lain mampu melepaskan stres melalui kegiatan fisik, mampu rileks tanpa tergantung pada perintah pelatih, mampu melakukan kegiatan yang nyaman dan menenangkan bagi dirinya, mampu menguasai teknik dan strategi pertandingan, mampu mengembangkan strategi mental, mampu membangun kepercayaan tinggi dan mampu memberikan makna yang proporsional terhadap kekalahan (Putri, 2016).

Hal ini yang perlu ditingkatkan pada atlet Pade Angen Mataram Hal ini muncul dalam Soerjoatmodjo, Moningka dan Angkawijaya (2017) yang mengungkapkan bahwa saat kalah bertanding, atlet Persatuan Tenis meja Pade anggen mataram merasa tidak percaya, sedih, minder, kecewa, malu, dongkol, frustrasi, merasa diri sendiri bagaikan pecundang, stres, takut, merasa gagal, tidak bisa tidur, tidak nafsu makan, ingin menyendiri sampai ingin menyerah. Penelitian lain menunjukkan potret yang tak jauh berbeda.

Penelitian terhadap 50 pelajar atlet di GOR Pade Angen Mataram Rembiga Mataram menguraikan ada empat stressor atau sumber stres yakni (1) physical stressor atau tuntutan fisiologis terhadap fisik atlet, (2) social stressor atau sumber stres yang timbul dari interaksi individu dengan individu lain, (3) psychological. stressor atau sumber stres yang timbul dari rasa frustrasi, kecemasan maupun konflik, dan (4) endemic stressor atau sumber stres yang tidak dapat dihindari atau disebabkan oleh faktor di luar kendali individu seperti duka cita (Widiani, 2011). Salah satu cara mempertahankan prestasi adalah meningkatkan fasilitas. GOR baru memiliki fasilitas meliputi 6 meja tenis meja lapangan dengan luas total 40 meter persegi GOR tersebut juga disinilah mereka berlatih selama 4 hari dalam seminggu, dimulai dari pukul 15.00-18.00 Wita. 
Jadwal keseharian ini diawal dengan latihan fisik di pagi hari, kegiatan akademik di Sekolah tenis meja, istirahat sejenak kemudian kembali bergelut dengan bet dan bola sampai malam.

Para atlet tersebut kemudian berlatih dan bertanding dalam lima partai yakni (1) tunggal putra, (2) tunggal putri, (3) ganda putra, (4) ganda putri, dan (5) ganda campuran. Atlet tenis meja menjalani latihan demi mencapai kondisi fisik yang salah satunya ditandai dengan volume oksigen pada paru-paru (Rana, 2012). Selain itu, atlet juga menjalani latihan teknik agar menguasai pukulan spin, smash, backhand dan forehand, dapat diarahkan ke tempat yang sulit dijangkau dijangkau lawan (Putri, 2016).

Pembinaan sejak dini secara sistematis dan terkonsentrasi ini penting mengingat bulutangkis merupakan cabang olahraga yang efektif dikembangkan sejak usia 11-12 tahun dan diharapkan mencapai puncak pada usia 20-25 tahun (Putri, 2016). Secara umum, atlet bulutangkis dikategorisasikan berdasarkan gender, usia dan cabang, sebagaimana tercermin pada Tabel 1.1 berikut

Tabel 1. 1 Kategorisasi Atlet Bulutangkis Berdasarkan Usia

\begin{tabular}{|c|c|}
\hline Usia & Kategori \\
\hline 10 tahun ke bawah & Anak \\
\hline $10-13$ tahun & Pemula \\
\hline $13-15$ tahun & Remaja \\
\hline $15-19$ tahun & Taruna \\
\hline 19 tahun ke atas & Dewasa \\
\hline
\end{tabular}

Dapat dilihat bahwa kelompok usia tersebut tergolong dalam kelompok anak, remaja sampai dewasa. Maka perlu diingat, seraya meraih prestasi, mereka juga menjalani transisi antara kelompok usia dengan tugas perkembangan berbeda-beda. Santrock (2011) menjelaskan

bahwa sepanjang periode tersebut, terjadi perubahan biologis, kognitif dan sosioemosional dalam upaya menemukan jati diri dan arah mereka dalam menjalani keseharian. Keterampilan psikologis menjadi penting dalam masa transisi ini. Tanpa keterampilan psikologis, atlet dapat dikuasai hal-hal yang mengganggu seperti masalah penyesuaian diri, stres, rasa cemas berlebihan dan sebagainya, yang mengakibatkan konsentrasi saat bertanding berpotensi terganggu sehingga berakibat pada atlet yang kurang optimal mencapai prestasi.

Oleh karena itu, atlet pada usia-usia tersebut membutuhkan dukungan sosial (social support) yaitu adanya orang lain di sekitar diri mereka yang dapat memberikan perasaan nyaman, memberikan perhatian pada kesejahteraannya, menaruh kepercayaan pada kemampuan mereka dan memberikan bantuan informasi positif yang memunculkan rasa tenang (Putri, 2016). Para atlet butuh bantuan agar dapat mengendalikan cara berpikir dan belajar yang memampukan mereka untuk mengolah emosi secara konstruktif. Salah satu cara adalah konseling.

Konseling adalah proses dialog yang terbuka, jujur dan bermakna antara konselor dan klien atau konseli dengan tujuan membantu klien mengatasi masalah dan meraih kesempatan melalui penerimaan atas persepsi dan perasaan tanpa menghakimi atau prasangka (Anshel, 2003). Konseling dirancang membantu konseli memahami masalah sehingga diperoleh insight yang membantunya menyelesaikan masalah serta menentukan langkah selanjutnya (Thompson, Rudoph \& Henderson, 2004).

Melalui konseling, atlet diajak berperan serta memahami keadaan atau situasi yang mereka alami. Moningka (2017) menyarankan juga konseling dapat mengasah keterampilan hidup (life skills). Sayangnya hingga saat ini, PB Pade Angen Mataram belum menyediakan layanan konseling bagi atlet-atletnya.

\section{METODE PELAKSANAAN PROGRAM PENGABDIAN MASYARAKAT}

Pendekatan dan metode pelaksanaan adalah riset aksi (action research) karena cara inilah yang bertujuan memberdayakan subyek dapat manfaat sebesar-besarnya, ketimbang mendudukkan mereka sebagai subyek pasif dalam eksperimen terkontrol (Giles, 2008).

Sebelum pelaksanaan, dilakukanlah pengukuran kebutuhan (need assessment) dengan proses pengukuran cepat (Rapid Assessment Process/RAP) yakni penggalian informasi 
kualitatif secara intensif dan berbasis pada tim menggunakan triangulasi, analisis data secara iteratif dan pengumpulan data tambahan untuk secara cepat membangun pemahaman dasar tentang satu situasi dari sudut pandang pelaku (Beebe, 2001). Hal tersebut dilakukan Soerjoatmodjo, Kaihatu, Moningka dan Angkawijaya (2017) dengan mengumpulkan data primer dan sekunder melibatkan pelatih teknik, pelatih fisik, guru, pengurus asrama dan atlet $\mathrm{PB}$ tenis meja Pade Angen Mataram serta dosen dan mahasiswa Program Studi Psikologi UNDIKMA (Jurusan Olahraga dan Bimbingan Konseling). Caranya dengan focus group discussion dan wawancara dilanjutkan dengan workshop perkenalan yang dilakukan sepanjang Oktober 2020, seperti tampak pada Gambar 1 di bawah ini

Variabel yang diamati adalah keterampilan mental atlet, dimana fokus konseling adalah membantu atlet mengembangkan keterampilan mental yang dibutuhkan dalam keseharian, saat berlatih dan saat bertanding.

Proses konseling dilakukan kolaboratif bersama dosen dan mahasiswa. Tiga orang dosen UNDIKMA (Jurusan Olahraga dan Bimbingan Konseling) berkualifikasi sebagai psikolog melakukan konseling pada Oktober 2020. Pelibatan mahasiswa dilakukan melalui mata kuliah Observasi dan Wawancara. Dua puluh tiga mahasiswa sebelumnya mendapatkan briefing dan mengobservasi situasi pertandingan pada kompetisi internasional Pembangunan PB. Tridatu Bali Vs Pade Angen Junior pada tanggal 17-20 Oktober 2020 seperti tampak pada Gambar 1. 1 di bawah ini

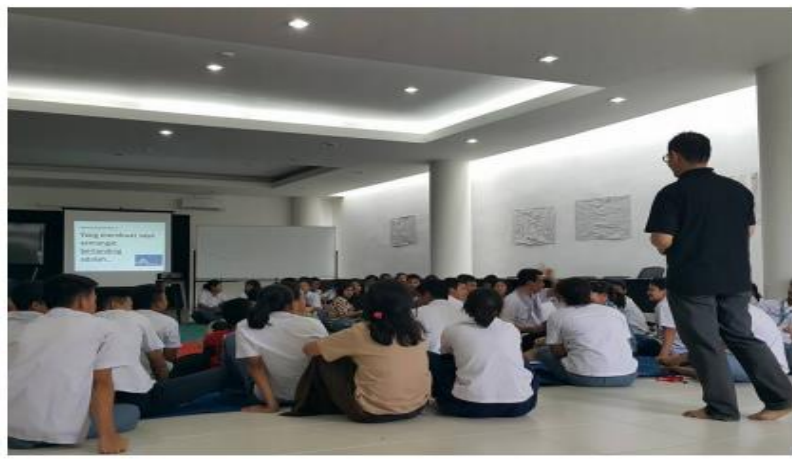

Gambar 1.1 Pengumpulan Atlet Tenis Meja...
Observasi Situasi Pertandingan, GOR PB Pade Angen, Juli 2020 Secara keseluruhan, pelaksanaan konseling dilakukan Juli-Oktober 2020 baik di PB Pade Angen Kota Mataram maupun di area public lapangan, sebagaimana tampak pada
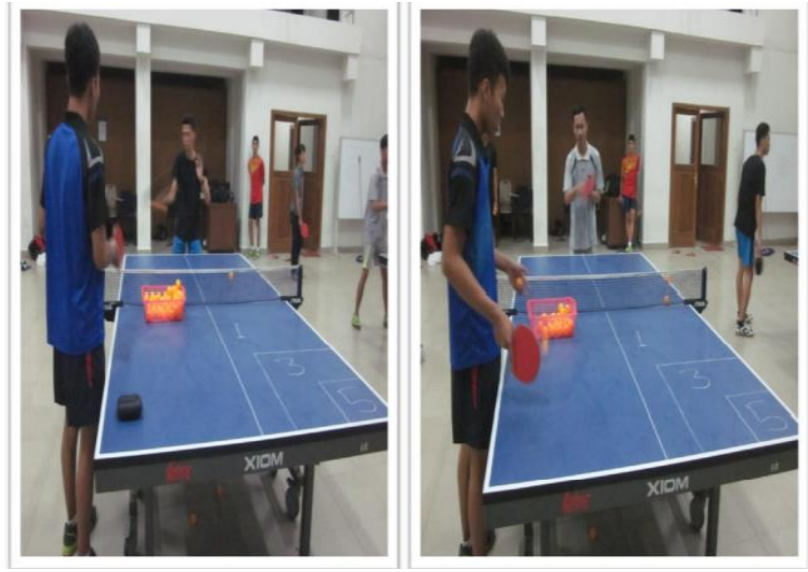

Gambar 1.2 berikut ini

Gambar 1.3. Konseling, PB Pade Angen, Juli 2020 Alat yang digunakan adalah panduan konseling yang disusun merujuk pada sembilan keterampilan mental dari Lesyk (2007) sebagaimana dapat dilihat pada

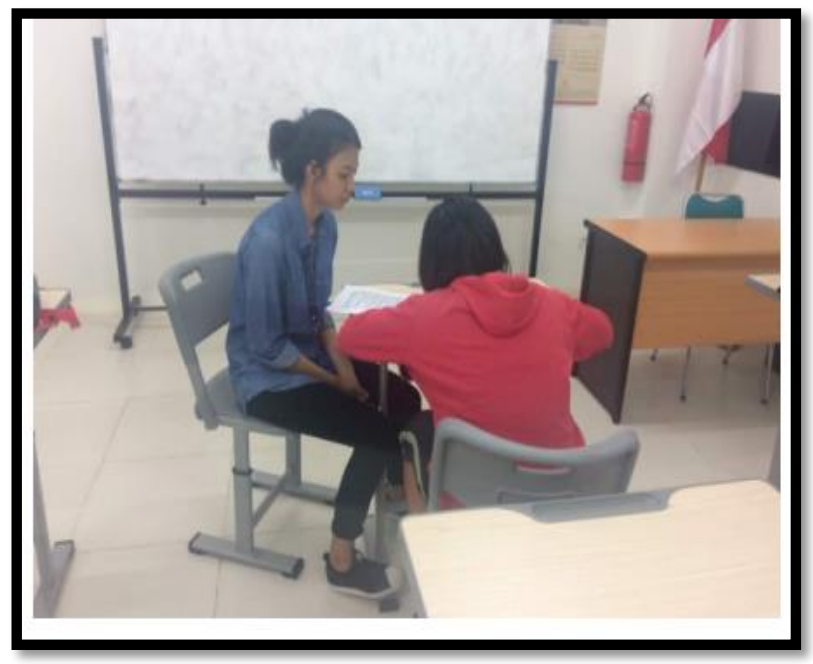

Gambar 1.3 konseling

Alat yang digunakan adalah panduan konseling yang disusun merujuk pada sembilan keterampilan mental dari Lesyk (2007) sebagaimana dapat dilihat pada Tabel 2 berikut. 
Tabel 1.2 keterampilan mental atlet yang berhasil keterampilan

\begin{tabular}{|c|c|c|c|c|}
\hline Level & Tingkat & Konteks & Keterampilan & Uraian \\
\hline \multirow[t]{4}{*}{1} & \multirow[t]{4}{*}{$\begin{array}{l}\text { Basic } \\
\text { Skills }\end{array}$} & \multirow[t]{4}{*}{ Kescharian } & Sikap (Attitude) & $\begin{array}{l}\text { Mampu memilih sikap positif terhadap } \\
\text { pilihan untuk berkarir sebagai atlet }\end{array}$ \\
\hline & & & Motivasi (Motivation) & $\begin{array}{l}\text { Mampu mengidentifikasi hal-hal yang } \\
\text { memberi motivasi }\end{array}$ \\
\hline & & & $\begin{array}{l}\text { Tujuan dan Komitmen } \\
\text { (Gouls and } \\
\text { Commitment) }\end{array}$ & $\begin{array}{l}\text { Mampu menetapkan target dan } \\
\text { berkomitmen mencapai tujuan }\end{array}$ \\
\hline & & & $\begin{array}{l}\text { Menjalin Hubungan } \\
\text { dengan Orang Lain } \\
\text { (People Shills) }\end{array}$ & $\begin{array}{l}\text { Mampu menempatkan din dalam sistem } \\
\text { sosial, dapat membangun hubungan } \\
\text { serta efektif mengelola konflik }\end{array}$ \\
\hline \multirow[t]{2}{*}{2} & \multirow[t]{2}{*}{$\begin{array}{l}\text { Prepa: } \\
\text { ratory } \\
\text { Skills }\end{array}$} & \multirow{2}{*}{$\begin{array}{l}\text { Latihan } \\
\text { menjelang } \\
\text { pertan- } \\
\text { dingan }\end{array}$} & $\begin{array}{l}\text { Berbicara dengan Diri } \\
\text { Sendin(Self Talk) }\end{array}$ & $\begin{array}{l}\text { Mampu berbicara pada diri sendin } \\
\text { seolah-olah sedang berbicara pada } \\
\text { sahabat }\end{array}$ \\
\hline & & & $\begin{array}{l}\text { Membangun Imajeri } \\
\text { Mental (Mental } \\
\text { Imageny) }\end{array}$ & $\begin{array}{l}\text { Mampu membayangkan diri sendin } \\
\text { berhasil pada saat bertanding }\end{array}$ \\
\hline \multirow[t]{3}{*}{3} & \multirow[t]{3}{*}{$\begin{array}{l}\text { Perfor. } \\
\text { mance } \\
\text { Skills }\end{array}$} & \multirow{3}{*}{$\begin{array}{l}\text { Unjuk } \\
\text { kemam- } \\
\text { puan saat } \\
\text { bertanding }\end{array}$} & $\begin{array}{l}\text { Mengelola Kecemasan } \\
\text { (Dealing with Anxiety) }\end{array}$ & $\begin{array}{l}\text { Mampu menerima kecemasan sebagai } \\
\text { bagian dari menjalani pertandingan dan } \\
\text { mengetahui cara menurunkannya }\end{array}$ \\
\hline & & & $\begin{array}{l}\text { Mengelola Emosi } \\
\text { (Dealing with } \\
\text { Emotion) }\end{array}$ & $\begin{array}{l}\text { Mampu menerima emosi, } \\
\text { mengungkapkan secara tepat dan } \\
\text { menggunakan emosi untuk } \\
\text { meningkatkan performa } \\
\end{array}$ \\
\hline & & & $\begin{array}{l}\text { Berkonsentrasi } \\
\text { (Concentration) }\end{array}$ & $\begin{array}{l}\text { Mampu mempertahankan konsentrasi, } \\
\text { fokus pada pertandingan }\end{array}$ \\
\hline
\end{tabular}

Secara keseluruhan, setiap konseling dilakukan secara tatap muka dalam durasi 45-90 menit yang kemudian ditranskripsi sepanjang Juli 2020 Transkripsi kemudian ditelaah tim dosen selama Juli-Agustus 2020 untuk memberikan penilaian, yaitu Baik (B), Cukup (C) dan Kurang (K) seperti pada Tabel 3 .

Tabel 1.3 Tabel Penilaian Keterampilan Mental

\begin{tabular}{|l|l|l|l|l|}
\hline N0 & KETERAMPILAN & BAIK & CUKUP & SEDANG \\
\hline 1 & Sikap (Attitude) & & & \\
\hline 2 & Motivasi (Motivation) & & & \\
\hline 3 & Tujuan dan Komitmen (Goals and Commitment) & & & \\
\hline 4 & Membangun Imajeri Mental (Mental Imagery) & & & \\
\hline
\end{tabular}

Penilaian difinalisasi pada oktober 2020. Analisis data dilakukan deskriptif dengan menghitung frekuensi jumlah penilaian Baik, Cukup dan Kurang untuk sembilan keterampilan mental dengan hasil yang dituangkan dalam grafik, yang dilakukan pada akhir Oktober 2020.

\section{HASIL DAN PEMBAHASAN}

Hasil pengabdian masyarakat adalah sebagai berikut. Total 62 atlet yang mendapat layanan konseling atlet dengan komposisi gender seimbang, seperti pada Gambar 1. 4.

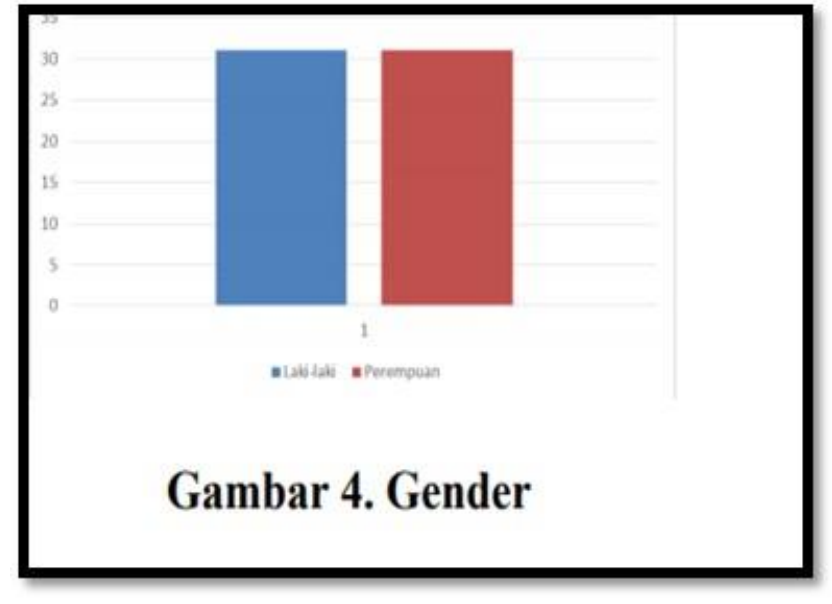

Mayoritas subyek berada di usia remaja,

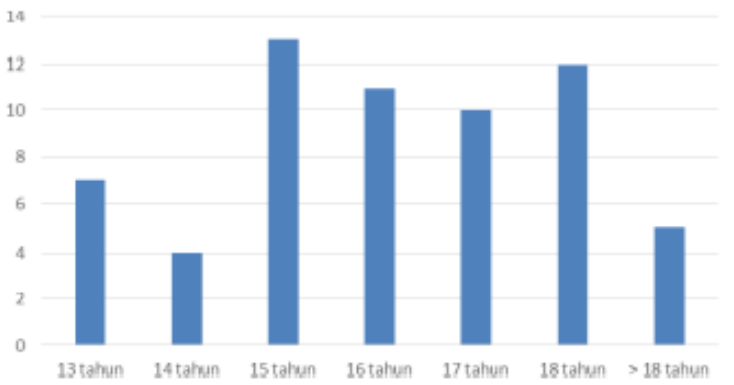

\section{Gambar 5. Usia}

sebagaimana tampak pada Gambar 5 berikut

Hasil untuk sembilan keterampilan mental adalah sebagai berikut. Bagian pertama ini menguraikan keterampilan dasar yang dibutuhkan dalam konteks keseharian yaitu sikap, motivasi, tujuan dan komitmen serta keterampilan berhubungan dengan orang lain. 1. Sikap (Attitude) Atlet dengan sikap baik adalah mereka yang bersikap positif pada pilihan karir sebagai atlet. Sebagian besar mempunyai sikap tersebut seperti pada Gambar 6 berikut. 


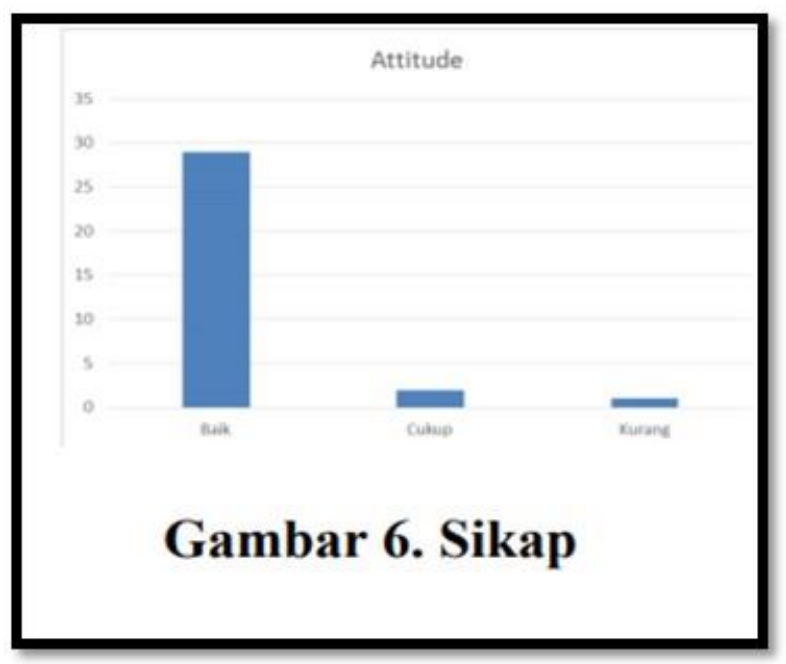

Motivasi (Motivation) Atlet dengan motivasi baik adalah mereka yang mampu mengidentifikasi halhal yang menggerakkannya. Gambar 7 berikut menunjukkan sebagian besar memiliki motivasi baik.

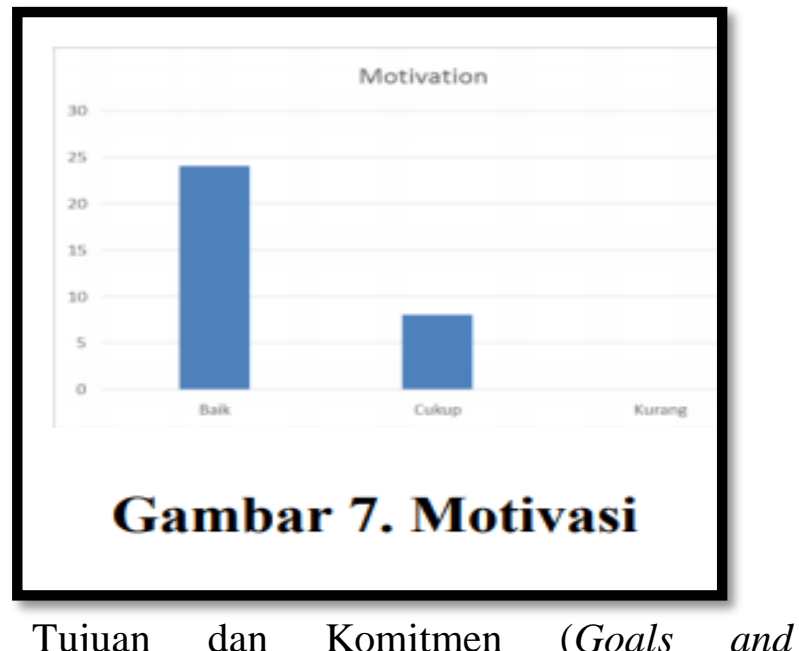

Commitment) Atlet dengan tujuan dan komitmen baik adalah mereka yang mampu menetapkan target dan berkomitmen memegang tujuan. Sementara sebagian memiliki tujuan dan komitmen yang baik, komposisi mereka dengan tujuan dan komitmen cukup dan kurang kurang lebih setara.

Membangun Imajeri Mental (Mental Imagery) Atlet yang mampu membangun imajeri mental adalah mereka yang dapat membayangkan diri sendiri berhasil saat bertanding. Dapat dilihat bahwa jummlah mereka yang kurang mampu lebih banyak dibandingkan mereka yang sanggup membangun imajeri mental secara baik.

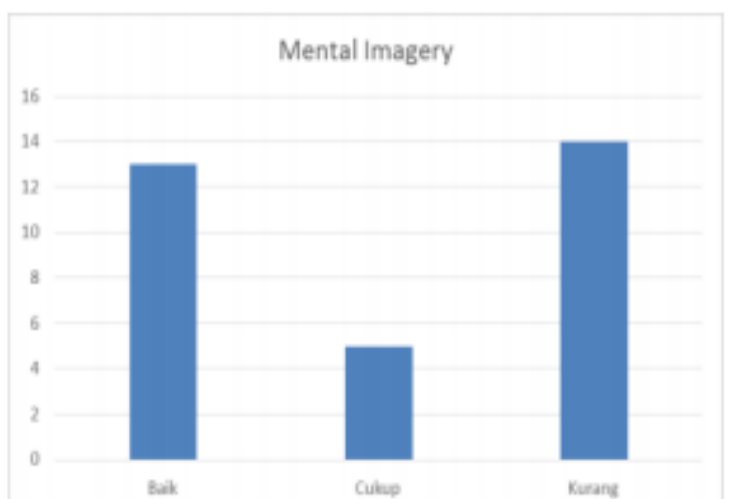

Dengan melihat gambaran di atas, dapat dilihat atlet Jaya Raya butuh peningkatan keterampilan mental pada aspek self talk dan mental imagery.

\section{SIMPULAN}

Temuan pengabdian masyarakat menyimpulkan bahwa keterampilan psikologis atlet PB Pade Angen Mataram serta dosen dan mahasiswa Program Studi Psikologi UDIKMA (Jurusan Olahraga dan Bimbingan Konseling). berada yang cukup. Pengabdian masyarakat ini menyarankan peningkatan kapasitas khususnya pada aspek self talk dan mental imagery, yang diharapkan nantinya berkontribusi pada dealing with anxiety.

Ucapan terimakasih diberikan kepada PB

Tenis Meja Pade Angen Mataram, dimana sejak Maret 2017 kolaborasi PB Jaya Raya-PSI UPJ ini dipayungi MoU (Memorandum of Understanding) tingkat universitas dan MoA (Memorandum of Agreement) tingkat program studi. Ucapan terimakasih juga diberikan pada Lembaga Penelitian dan Pengabdian Masyarakat (LPPM UNDIKMA) atas dukungan hibah Ipteks Bagi Masyarakat selama durasi 6 bulan, termasuk juga untuk dukungan hibah Penelitian Unggulan Perguruan Tinggi yang digunakan untuk menindaklanjuti saran dari pengabdian masyarakat ini.

\section{SARAN}

Bagi atlet sebagai masukan untuk lebih meningkatkan latihan kemampuan ketepatan 
Teknik dasar permaian tenis meja, sehingga dapat tampil lebih baik dalam suatu pertandingan dan dapat mencapai prestasi optimal. Bagi pelatih atau guru untuk memberikan latihan yang bervariasi lagi sebagai upaya untuk meningkatkan kemampuan Teknik dasar permaian tenis meja. Perlu diadakan penelitian lanjutan dengan menambah variabel lain. Dalam penelitian ini masih banyak kekurangan, untuk itu bagi peneliti selanjutnya hendaknya menghembangkan dan menyempurnakan instrumen penelitian.

\section{DAFTAR PUSTAKA}

Wondowisnowo, B.H. 2016. 40 tahun PB Jaya Raya Tak Pernah Henti Lahirkan Juara, Jakarta: Yayasan Pembangunan Jaya Raya.

Gunarsa, S. D. 2008. Psikologi Olahraga Prestasi. Jakarta: PT BPK Gunung Mulia

Putri, D. 2016. Gambaran Penerapan Managing Anxiety pada Atlet Tunggal Taruna di Klub Bulutangkis "XYZ" Universitas Pembangunan Jaya: Skripsi.

Soerjoatmodjo, G.W.L., Moningka, C. \& Angkawijaya, Y.F. 2018. Juara Juga Manusia.

Buletin Konsorsium Psikologi Ilmiah Nusantara $\begin{array}{lllll}\text { Vol } 3 & \text { No } 21 & \text { Januari } & 2018\end{array}$ [http://buletin.k-pin.org/index.php/arsipartikel/228-juara-juga-manusia].

Williams, J.M. \& Straub, W.F. 2010. Sport Psychology: Past, Present, Future New York: McGraw-Hill.

Soerjoatmodjo, G.W.L., Kaihatu, V. Moningka, C. \& Angkawijaya, Y.F. 2017. Prospek Kebutuhan Layanan Psikologis untuk Atlet Jaya Raya.

Fakultas Psikologi Universitas Islam Negeri Syarif Hidayatullah Jakarta: Skripsi. 9. Bulutangkis.com. 2016. PB Jaya Raya Bangun Fasilitas Pelatihan Baru di Bintaro. $14 \quad$ September [http://www.bulutangkis.com/mod.php? mod $=$ publisher\&op $=$ viewarticle\&artid=103466]

Santrock, J.W. 2011. Life-Span Development. 14th Edition. New York: McGraw-Hill
Rana, M.S. 2012. Assessment of Physiological Variables of Badminton Players, International Journal of Behavioral Social and Movement Sciences Vol. 01, Issue 04, Okt.hlm. 45-59

Soerjoatmodjo, G.W.L., Moningka, C. \& Angkawijaya, Y.F. 2017. Membangun Mental Juara. Info Bintaro. 29 Agustus [https://www.infobintaro.com/membang un-mentaljuara/]

Anderson, A.G., Miles, A., Mahoney, C. \& Robinson, C. 2002. Evaluating the Effectiveness of Applied Sport Psychology Practice: Making the Case for a Case Study Approach. The Sport Psychologist. Vol. 16 No. 4. hlm. 432453

Anshel, M.H. 2003. Sport Psychology: From Theory to Practice. 4th Edition San Fransisco: Pearson Education. 15. Thompson, C.L. Rudoph, L.R. \& Henderson, D.A. 2004.

Conselling Children. 6th Edition. California: Brooks/Cole-Thomson Learning 16. Moningka, C. 2017. Life Skills untuk Atlet di Indonesia .

Buletin Konsorsium Psikologi Ilmiah Nusantara $\begin{array}{llllll}\text { Vol } 3 & \text { No } & 10 & \text { Oktober } & 2017\end{array}$ [http://buletin.kpin.org/index.php/daftarartikel/201-lifeskills-untuk-atlet-di-indonesia]

Giles, D. 2008. Advanced Research Methods in Psychology New York: Routledge, 2008.

Beebe, J. 2001. Rapid Assessment Process: An Introduction Oxford: AltaMira Press.

Lesyk (2007). The Nine Mental Skills of Successful Athletes: A Holistic Model for Assessing and Teaching Mental Skills to Athletes. Sport Psychologist. Vol 11. hlm.1-6

Widyakala. Volume 4 No 1 Maret 2017. hlm 1120. 8. Widiani, H. (2011). Sumber Stres dan Strategi Coping pada Pelajar Atlet Bulutangkis.

Kompas. 2016. PB Jaya Raya Ingin Kejar Ketinggalan. $\quad 15 \quad$ September. [http://olahraga.kompas.com/read/2016/ 
Abdi Masyarakat

http://ejournal.mandalanursa.org/index.php/PB/issue/archive

09/15/17292751/pb.jaya.raya.ingin.kejar

.ketertin ggalan]
Vol. 2. No. 2 Desember 2020

p-ISSN: 2715-8799 e-ISSN: 2715-9108 